\title{
Role of Thromboxane and Prostacyclin in Pulmonary Vasomotor Changes after Endotoxin in Dogs
}

\author{
C. A. Hales, L. Sonne, M. Peterson, D. Kong, M. Miller, and W. David Watkins, \\ Departments of Medicine (Pulmonary) and Anesthesia, Massachusetts General \\ Hospital and Harvard Medical School, Boston, Massachusetts 02114
}

A B S T R A C T Cyclooxygenase inhibitors prevent the pulmonary vasomotor changes in response to low-dose endotoxin. We, therefore, explored the role of two highly vasoactive prostanoids, thromboxane $\mathrm{A}_{2}$, a vasoconstrictor, and prostacyclin, a vasodilator, in the transient pulmonary vasoconstriction and subsequent loss of alveolar hypoxis vasoconstriction (AHPV) that follows endotoxin. AHPV was tested in the dog with a double-lumened endotracheal tube allowing ventilation of one lung with nitrogen as a hypoxic challenge while the other lung was ventilated with oxygen to maintain systemic oxygenation. Relative distribution of perfusion to the two lungs was assessed with intravenous ${ }^{133} \mathrm{Xe}$ and external scintillation detectors. The stable metabolites of thromboxane and prostacyclin, i.e., thromboxane $B_{2}$ and 6-keto-prostaglandin $F_{1 \alpha}$ were measured in plasma with radioimmunoassay. $15 \mu \mathrm{g} / \mathrm{kg}$ i.v. of endotoxin induced no rise in pulmonary vascular resistance (PVR), but prevented AHPV so that the initial $33 \%( \pm 2$ SEM) decrease in perfusion to the hypoxic lung became only a $2 \%( \pm 1)$ decrease. Circulating levels of thromboxane and prostacyclin concurrently rose $(P<0.01)$ from nondetectable levels to $380 \mathrm{pg} / \mathrm{ml}( \pm 40)$ and $360 \mathrm{pg} / \mathrm{ml}( \pm 130) .150 \mu \mathrm{g} / \mathrm{kg}$ of endotoxin induced a transient rise in PVR from 4.09 to $9.00 \mathrm{~mm} \mathrm{Hg} /$ liter per min in association $(r=0.89$, $P<0.01$ ) with a sharp rise in thromboxane levels to $4,460 \mathrm{pg} / \mathrm{ml}( \pm 1,350)$ whereas prostacyclin levels were elevated less markedly to $550 \mathrm{pg} / \mathrm{ml}( \pm 400)$. Prostaglandin $F_{2 \alpha}$, another vasoconstrictor, was not elevated. 30 min after endotoxin when PVR was again base line and AHPV lost, thromboxane fell significantly $(P<0.01)$ to $2,200 \mathrm{pg} / \mathrm{ml}( \pm 1,100)$ whereas prostacyclin remained elevated at $360 \mathrm{pg} / \mathrm{ml}( \pm 135)$, a level similar to that seen when $15 \mu \mathrm{g} / \mathrm{kg}$ of endotoxin induced

Dr. Peterson is an Established Investigator of the American Heart Association.

Received for publication 11 December 1980 and in revised form 24 February 1981. loss of AHPV. Indomethacin prevented the rise in thromboxane and prostacyclin after endotoxin as well as the changes in pulmonary vasomotor tone. Thus, a complex interaction between thromboxane and prostacyclin is involved in the pulmonary vasomotor response to low-dose endotoxin.

\section{INTRODUCTION}

Endotoxin, in large doses, produces shock accompanied by changes in pulmonary vascular tone and permeability. The physiologic response to endotoxin results from a complex interaction of reactive oxygen radicals (1), complement (2), leukocytes (3), and platelets (4) to increase circulating levels of proteolytic enzymes and vasoactive substances such as histamine $(5,6)$, kinins $(5)$, serotonin $(5,7)$, prostanoids $(8,9)$, and endorphins (10). Endotoxin in small doses does not produce shock in the dog but does cause transient pulmonary hypertension followed by a period of pulmonary vascular hyporesponsivity to most agonists including hypoxia (11). Although pulmonary production of prostanoids has been directly shown only after a large dose of endotoxin, there is considerable indirect evidence that prostanoids are the major vasoactive intermediaries of the biphasic pulmonary vascular response to low-dose endotoxin (12-14). These studies have all used cyclo-oxygenase inhibitors such as aspirin or indomethacin, and it is possible the drugs blocked endotoxin's effect in some fashion other than through inhibiting cyclo-oxygenase. Therefore, we have sought to clarify the relationship of prostanoids to pulmonary vascular tone by correlating tone changes after endotoxin infusion with endogenous production of two prostanoids, thromboxane and prostacyclin. High circulating levels of thromboxane occur in the rat after endotoxin in doses that cause shock (15). Thromboxane $A_{2}$ is probably a potent pulmonary and systemic vasoconstrictor but cannot be produced in sufficient quantities to test this thesis directly $(16,17)$. Prostacyclin, on the other hand, is a strong pulmonary 
vasodilator and the only known pulmonary vasodilator besides prostaglandin $\mathrm{E}_{1}$ that is a comparatively weak vasodilator (18). Prostacyclin has been observed to increase 5-30 min after shock doses of endotoxin in the rabbit where it seems partially responsible for the ensuing systemic hypotension (19). We wondered then if endotoxin's variable effects on pulmonary vasomotor tone could be explained by an interaction of the probable pulmonary vasoconstrictor thromboxane $A_{2}$ and the pulmonary vasodilator prostacyclin. We hypothesized, therefore, that the transient rise in pulmonary artery pressure after low-dose endotoxin was caused by an excess of thromboxane production, but with time prostacyclin became the predominant pulmonary influence with resulting hyporesponsivity of lung vessels to vasconstrictors such as hypoxia, angiotensin II, or prostaglandin $F_{2 \alpha}$. Because the halflives of thromboxane $A_{2}$ and prostacyclin are too short to allow for direct measurements, we performed radioimmunoassay of the stable metabolites of these two prostanoids, thromboxane $B_{2}$ and 6-keto-prostaglandin $\mathrm{F}_{1 \alpha}\left(6 \mathrm{KPGF}_{1 \alpha}\right) .^{1}$

\section{METHODS}

Reactivity of pulmonary vessels to hypoxia was assessed using a dog model of alveolar hypoxia produced by use of a double-lumened endotracheal tube. Ventilation of one lung with nitrogen produces alveolar hypoxia to that lung, while ventilation of the other lung with oxygen maintains near normal systemic oxygenation, thus preventing changes in cardiac output or systemic acidosis that could alter pulmonary vascular reactivity.

Mongrel dogs, weighing 18-38 $\mathrm{kg}$ were anesthetized with intravenous sodium pentobarbital $(30 \mathrm{mg} / \mathrm{kg}$ ) followed by repetitive two hourly doses of $4.5 \mathrm{mg} / \mathrm{kg}$. A double lumen endotracheal tube (Rusch) was passed to the carina and the balloon inflated to separate the two main bronchi. Connected to a volume-cycled dual ventilator (Harvard Apparatus Co., Inc., Millis, Mass.), each lung received a separate tidal volume of $7.5 \mathrm{~cm}^{3} / \mathrm{kg}$ at a rate of $14-16$ cycles/ min. Both lungs were ventilated with room air between experimental runs. Airway pressures were continuously monitored from both lungs by pressure transducers connected to a side arm of each tracheal cannula. To prevent atelectasis, both lungs were hyperinflated every 10 $\min$ and 2 min before each perfusion study by raising expiratory airway pressure to $30 \mathrm{~mm} \mathrm{Hg}$ by occluding the expiratory ports of the ventilator. Tracheal division was tested by ventilating one lung with $100 \% \mathrm{O}_{2}$ and the other with $100 \% \mathrm{~N}_{2}$, while measuring end-tidal $\mathrm{Po}_{2}$ from the nitrogen-ventilated lung. As previously described (20), an endtidal $\mathrm{PO}_{2}$ of $<30 \mathrm{~mm} / \mathrm{Hg}$ after $7 \mathrm{~min}$ of $\mathrm{N}_{2}$ breathing was considered adequate division. This was verified before and after each hypoxic perfusion study.

Polyethylene catheters were placed in each femoral artery

\footnotetext{
${ }^{1}$ Abbreviations used in this paper: A II, angiotensin II; $6 \mathrm{KPGF}_{1 \alpha}$, 6-keto-prostaglandin $\mathrm{F}_{1 \alpha}, \mathrm{PGF}_{2 \alpha}$, prostaglandin $F_{2 \alpha} ;$ PVR, pulmonary vascular resistance; $\mathrm{TxB}_{2}$, thromboxane $B_{2}$.
}

for measurement of arterial pressure and cardiac output. Catheters were inserted through both femoral veins into the inferior vena cava for all injections. Using the contour of the pressure pulses as a guide, Swan-Ganz catheter was passed through the jugular vein into the pulmonary artery, for determination of pulmonary artery and pulmonary capillary wedge pressure. A second Swan-Ganz catheter was passed into the main pulmonary artery for mixed venous blood sampling. $\mathrm{PO}_{2}, \mathrm{PCO}_{2}$, and $\mathrm{pH}$ in blood samples were determined with appropriate electrodes at $38^{\circ} \mathrm{C}$ (models 127 and 213; Instrumentation Laboratory, Inc., Lexington, Mass.).

Distribution of pulmonary perfusion was determined with ${ }^{133} \mathrm{Xe}$ and external chest detectors (21). Four sodium iodide (TI) crystals, $32 \mathrm{~mm}$ in Diam and $25 \mathrm{~mm}$ in height with $10 \mathrm{~cm}$ deep divided lead collimators, two for each lung, were positioned over the anterior thorax of the supine animal. The counters were at a $7^{\circ}$ angle of divergence from the midsagittal plane, which previous isocount curves have shown to result in less than a $5 \%$ overlap of counts between the two lungs. $1 \mathrm{mCi}$ of ${ }^{133} \mathrm{Xe}$ in $1 \mathrm{ml}$ of saline was injected intravenously during a 15-s breathhold at end-tidal inspiration. Counts from each detector, represented by a plateau of activity during breathhold, were recorded simultaneously on magnetic tape and later transcribed on a X-Y recorder. Counts from the upper and lower counter over each lung were summed and expressed as a percentage of total counts to both lungs. This fraction was assumed to represent relative perfusion to that lung.

Control. Baseline relative distribution of perfusion to each lung was determined for each dog while breathing room air. Before ${ }^{133} \mathrm{Xe}$ injection, arterial blood gases, airway pressures from both lungs, arterial blood pressure, pulmonary artery, and pulmonary capillary wedge pressure were measured and recorded. Cardiac output was measured by dye-dilution technique using a cardiac output computer and clinical densitometer (model RLD; Lexington Instruments Corp., Waltham, Mass.).

As a hypoxic challenge, $100 \%$ nitrogen was administered to the test lung with $100 \%$ oxygen delivered to the other lung to maintain adequate systemic oxygenation. The test lung was chosen randomly for each dog and remained the same throughout the experiment. Blood sampling, cardiac output, and pressure measurements were performed as before, after $7 \mathrm{~min}$ of unilateral nitrogen ventilation. Relative perfusion to each lung was expressed both as percentage of total counts, and as percent decrease in perfusion from the room air control value. Previous investigations, with this model, have shown the hypoxic vasoconstrictor response to be maximal at $7 \mathrm{~min}$ and stable for $30 \mathrm{~min}$ after initiation of unilateral nitrogen ventilation (22). Hence, all hypoxic challenge relative to perfusion measurements were made after $7 \mathrm{~min}$ of unilateral nitrogen ventilation.

Animals were returned to bilateral room air breathing for $10 \mathrm{~min}$ before another experimental run. This entire procedure was repeated at least three times, and only animals that established a reproducible base-line room air perfusion decrease with unilateral hypoxia were used in the study (23). The mean of the three base-line responses was used as the control hypoxic response.

Airway pressures were equal in both tracheal cannulae ( $6 \mathrm{~mm} \mathrm{Hg} \pm 0.2 \mathrm{SEM}$ ) during ventilation with air and did not change significantly during unilateral alveolar hypoxia nor with any other experimental condition.

Mixed venous and aortic blood samples were obtained on room air and during hypoxia for prostanoid analysis In some animals, mixed venous and aortic blood samples were also obtained for platelet counts.

Endotoxin. After all base-line measurements had been 
accomplished, Escherichia coli endotoxin (lot 055: B5651873; Difco Laboratories, Detroit, Mich.) in saline was infused into the inferior vena cava in a bolus of 15 or $150 \mu \mathrm{g} / \mathrm{kg}$. All measurements and blood sampling were repeated except for the xenon distribution of perfusion at 1 and $5 \mathrm{~min}$ after endotoxin injection at a time when the rise in pulmonary artery pressure was maximum. $20 \mathrm{~min}$ after endotoxin, ${ }^{133} \mathrm{Xe}$ distribution of perfusion on room air was performed, and the animal was placed on unilateral alveolar hypoxia. 10 min later ${ }^{133} \mathrm{Xe}$ distribution of perfusion, as well as all other parameters, were again recorded.

To determine if endotoxin was a specific inhibitor of alveolar hypoxia or was a general pulmonary vascular relaxant, an additional five dogs were infused with the pulmonary vasoconstrictors prostaglandin $\mathrm{F}_{2 \alpha}\left(\mathrm{PGF}_{2 \alpha}\right)$ (courtesy of Dr. John Pike; UpJohn Co., Kalamazoo, Mich.) or angiotensin II (A II). A continuous infusion of $0.15 \mu \mathrm{g} / \mathrm{kg}$ per min of $\mathrm{PGF}_{2 \alpha}$ or A II was begun. Mean pulmonary artery pressure, pulmonary capillary wedge pressure, and cardiac output were recorded before and during the infusion when stable pressures had been achieved. This procedure was repeated $30 \mathrm{~min}$ after endotoxin with the same doses of $\mathrm{PGF}_{2 \alpha}$ and A II.

Three dogs given $15 \mu \mathrm{g} / \mathrm{kg}$ of endotoxin and three dogs given $150 \mu \mathrm{g} / \mathrm{kg}$ of endotoxin were pretreated with $12 \mathrm{mg} / \mathrm{kg}$ of indomethacin (Merck Chemical Div., Merck \& Co., Inc., Rahway, N. J.) given as an intravenous infusion in phosphatebuffered saline. Serum indomethacin levels were determined by fluorescence spectrophotometry by National Medical Service (Willow Grove, Pa.). Five dogs were infused with imidazole (Aldrich Chemical Co., Inc., Milwaukee, Wis.) at 30 $\mathrm{mg} / \mathrm{kg}$ in $50 \mathrm{~cm}^{3}$ of saline to determine the influence on pulmonary vasoconstriction. Imidazole is alleged to inhibit thromboxane synthetase (15). After pretreatment with imidazole, an additional four dogs were given endotoxin at $150 \mu \mathrm{g} / \mathrm{kg}$ to determine the importance of thromboxane to the vasomotor changes induced by endotoxin.

Eicosanoid assay: plasma preparation. Aortic and mixed venous blood samples $(5 \mathrm{ml})$ were slowly drawn from indwelling catheters into sterile disposable 6-ml plastic syringes (Becton, Dickinson \& Co., Rutherford, N. J.), transferred into glass test tubes through an 18-gauge needle, and immediately placed on ice. The tubes contained $0.05 \mathrm{ml}$ of $15 \%$ potassium EDTA. Control experiments were conducted in which either indomethacin (Merck Chemical) $(25 \mu \mathrm{g} / \mathrm{ml}$ whole blood) or sodium ibuprofen (UpJohn Co.) $(25 \mu \mathrm{g} / \mathrm{ml}$ whole blood) were added to tubes containing EDTA to document that generation of thromboxane $\mathrm{B}_{2}\left(\mathrm{TxB}_{2}\right)$ or $\left(6 \mathrm{KPGF}_{1 \alpha}\right)$ did not result from sample preparation. Blood samples were centrifuged at $4^{\circ} \mathrm{C}$ at $1,000 \mathrm{~g}$ for $10 \mathrm{~min}$ (model PR-500; Damon/IEC Div., Damon Corp., Needham Heights, Mass.). Plasma was separated into polypropylene tubes and was stored at $80^{\circ} \mathrm{C}$.

Radioimmunoassay. $\mathrm{PGF}_{2 \alpha}$ was measured directly in plasma by previously described double antibody radioimmunoassay $(24,25)$.

Plasma $\mathrm{TxB}_{2}$ was measured in the same manner and is described below. Standard $\mathrm{TxB}_{2}$ (UpJohn Co.) or unknowns were diluted to a volume of $0.2 \mathrm{ml}$ with $0.01 \mathrm{M}$ Tris at a $\mathrm{pH}$ of 7.4 containing $0.1 \%$ reagent grade gelatin (standard diluent used in all dilutions). To this volume was added 0.1 $\mathrm{ml}\left[{ }^{3} \mathrm{H}\right] \mathrm{TxB}_{2}(100-150 \mathrm{Ci} / \mathrm{mmol}, 15,000 \mathrm{cpm}$; New England Nuclear, Boston, Mass.) and $0.1 \mathrm{ml}$ of anti- $\mathrm{TxB}_{2}$ (Immunalysis) at a dilution of 1:4,000. Incubation was carried out for $1 \mathrm{~h}$ at $37^{\circ} \mathrm{C}$. Normal rabbit serum, at a dilution of $1: 25$, was added $(0.1 \mathrm{ml})$, and the solution was thoroughly mixed. Goat anti-rabbit serum $(0.1 \mathrm{ml}$ at a dilution of $1: 25)$ was added, mixed, and the solution was incubated for $18 \mathrm{~h}$ at $4^{\circ} \mathrm{C}$ before centrifugation at $2,500 \mathrm{~g}$ at $5^{\circ} \mathrm{C}$ for $45 \mathrm{~min}$. Residual fluid was removed with Whatman no. 7 filter paper (Whatman, Inc., Clifton, N. J.). To the pellet was added $0.2 \mathrm{ml}$ of $0.1 \mathrm{M} \mathrm{NaOH}$ and $2.8 \mathrm{ml}$ of scintillation fluid (formula 949, New England Nuclear) containing 12\% BBS-3 (Beckman Instruments, Inc., Fullerton, Calif.). Tritium was counted at $\sim 55 \%$ efficiency with a Packard Tri-Carb liquid scintillation counter (Packard Instrument Co., Inc., Downers Grove, Ill.). Binding and inhibition curves were constructed in both buffer and pooled plasma with undetectable concentrations of $\mathrm{TxB}_{2}$ and were identical. Absolute limits of the sensitivity of the antibody measurement were 6 and $300 \mathrm{pg}$ by Robbards Probit Analysis (26). Corrected concentrations of $50 \mathrm{pg}$ or less were taken as our lower limit of plasma $\mathrm{TxB}_{2}$ for convenience as the curve is still linear at this point, not requiring statistics. Cross-reactivity of the antibody at $\mathrm{B} / \mathrm{Bo} 50 \%$ was arachidonic acid $<0.1 \%, \mathrm{PGA}_{2}<0.01 \%, \mathrm{PGD}_{2} 2.5 \%$, $\mathrm{PGE}_{2} 0.26 \%, \mathrm{PGF}_{2 \alpha}<0.1 \%, 6 \mathrm{KPGF}_{1 \alpha}<0.1 \%$. All samples were measured in duplicate or triplicate, and plasma concentrations were averaged and reported as picograms per milliliter plasma.

Plasma 6KPGF ${ }_{1 \alpha}$ was measured the same way except standard $6 \mathrm{KPGF}_{1 \alpha}$ (UpJohn Co.), or unknowns were added at a volume of $0.5 \mathrm{ml}$. The $\left[{ }^{3} \mathrm{H}\right] 6 \mathrm{KPGF}_{1 \alpha}$-radiolabeled tracer was added at a volume of $0.1 \mathrm{ml}(100 \mathrm{Ci} / \mathrm{mmol}$, New England Nuclear) and contained $17,000 \mathrm{cpm}$. Specitic antisera was used at a dilution of 1:5,000 (Immunalysis). A slight deviation between binding curves was present at low amounts of $6 \mathrm{KPGF}_{1 \alpha}$ when constructed in plasma and buffer. This was corrected in each determination. Absolute limits of detection were 10 and $270 \mathrm{pg}$ by statistical analysis but for convenience corrected concentrations of $50 \mathrm{pg} / \mathrm{ml}$ or less were taken as our lower limit of plasma $6 \mathrm{KPGF}_{1 \alpha}$. Crossreactivity at $\mathrm{B} / \mathrm{Bo} 50 \%$ was arachidonic acid $<0.1 \%, \mathrm{PGA}_{2}$ $<0.1 \%, \mathrm{PGD}_{2} 0.3 \%, \mathrm{PGE}_{2} 2.1 \%, \mathrm{PGF}_{2 \alpha} 4.5 \%, \mathrm{TxB}_{2}<0.1 \%$. Plasma concentrations of the duplicate or triplicate samples were averaged and were recorded as picograms per milliliter of plasma.

Control experiments with human and animal blood clearly demonstrated that the addition of either indomethacin or ibuprofen to EDTA before the addition of whole blood did not alter the concentration of either $\mathrm{TxB}_{2}$ or $6 \mathrm{KPGF}_{1 \alpha}$ measured by our method. Thus, neither $\mathrm{TxB}_{2}$ or $6 \mathrm{KPGF}_{1 \alpha}$ was produced, in vitro, by sample preparation.

Statistics. All values, where appropriate, were examined by the $t$ test for paired values (27).

\section{RESULTS}

Endotoxin, $15 \mu \mathrm{g} / \mathrm{kg}$. Endotoxin produced no change over a 30 -min period in any hemodynamic measurements (Table I) and did not significantly alter the control blood gases with a $\mathrm{Pa}_{\mathrm{O}_{2}}$ of $91 \mathrm{~mm} \mathrm{Hg}( \pm 2$ $\mathrm{SEM}), \mathrm{Pa}_{\mathrm{CO}_{2}}$ of $38 \mathrm{~mm} \mathrm{Hg}( \pm 2 \mathrm{SEM})$, and arterial $\mathrm{pH}$ of $7.36( \pm 0.03 \mathrm{SEM})$. Endotoxin also did not alter the $49 \%$ ( \pm 2 SEM) distribution of perfusion to the test lung while ventilated with room air but dramatically blocked the ability of the test lung to decrease its perfusion during hypoxic ventilation (Fig. 1). The loss of vasoconstrictor ability was not unique to hypoxia, however, as the postendotoxin lung vessels also failed to constrict to A II and PGF Pa $_{2 \alpha}$ infusions (Table I). Mean wet-to-bloodless dry weight ratios in three of these lungs was 3.11 , which is normal in our laboratory (28), suggesting the pulmonary vascular hyporesponsivity 
TABLE I

Hemodynamic Values ( \pm SEM) after Endotoxin

\begin{tabular}{|c|c|c|c|c|c|c|}
\hline & \multicolumn{3}{|c|}{$15 \mu \mathrm{g} / \mathrm{kg}$ endotoxin } & \multicolumn{3}{|c|}{$150 \mu \mathrm{g} / \mathrm{kg}$ endotoxin } \\
\hline & Control & Maximum & $30 \mathrm{~min}$ & Control & Maximum & $30 \mathrm{~min}$ \\
\hline PAP, $m m ~ H g$ & $13 \pm 2$ & $13 \pm 2$ & $12 \pm 2$ & $14 \pm 2$ & $23 \pm 2^{*}$ & $13 \pm 2$ \\
\hline $\mathrm{PCW}, m m H g$ & $6 \pm 1$ & $6 \pm 2$ & $5 \pm 2$ & $5 \pm 2$ & $6 \pm 2$ & $6 \pm 2$ \\
\hline $\mathrm{CO}$, liter/min & $1.8 \pm 0.2$ & $1.7 \pm 0.3$ & $1.6 \pm 0.3$ & $2.2 \pm 0.4$ & $1.9 \pm 0.6$ & $2.1 \pm 0.3$ \\
\hline$\Delta$ PVR $F_{2 \alpha}, \%$ & $\begin{array}{c}79 \pm 11 \\
(n=5)\end{array}$ & & $13 \pm 8^{*}$ & $\begin{array}{c}84 \\
(n=2)\end{array}$ & & 6 \\
\hline$\triangle$ PVR AII, \% & $\begin{array}{c}80 \\
(n=2)\end{array}$ & & 4 & $\begin{array}{c}76 \\
(n=4)\end{array}$ & & 6 \\
\hline FAP, $m m \mathbf{H g}$ & $133 \pm 3$ & $135 \pm 3$ & $133 \pm 2$ & $144 \pm 4$ & $135 \pm 4$ & $131 \pm 5^{*}$ \\
\hline$\Delta$ FAP AII, $m m H g$ & $\begin{array}{c}60 \\
(n=2)\end{array}$ & & 30 & $\begin{array}{c}58 \\
(n=4)\end{array}$ & & 3 \\
\hline
\end{tabular}

Except when indicated the values are from eight dogs at each endotoxin dose. PAP, mean pulmonary pressure; PCW, mean pulmonary capillary wedge pressure; CO, cardiac output; FAP, mean femoral artery pressure; $\triangle \mathrm{PVR}$, percentage change from base line in pulmonary vascular resistance; $\triangle F A P$, millimeters change in femoral artery blood pressure.

${ }^{*} P<0.01$.

was not caused by pulmonary edema. Furthermore, the vascular hyporeactivity was not limited to the pulmonary vessels, but also seemed to involve the systemic vessels. This was apparent in the two dogs infused with A II in which the control rise in systemic blood pressure of $60 \mathrm{~mm} \mathrm{Hg}$ was reduced to $30 \mathrm{~mm} \mathrm{Hg}$ after endotoxin.

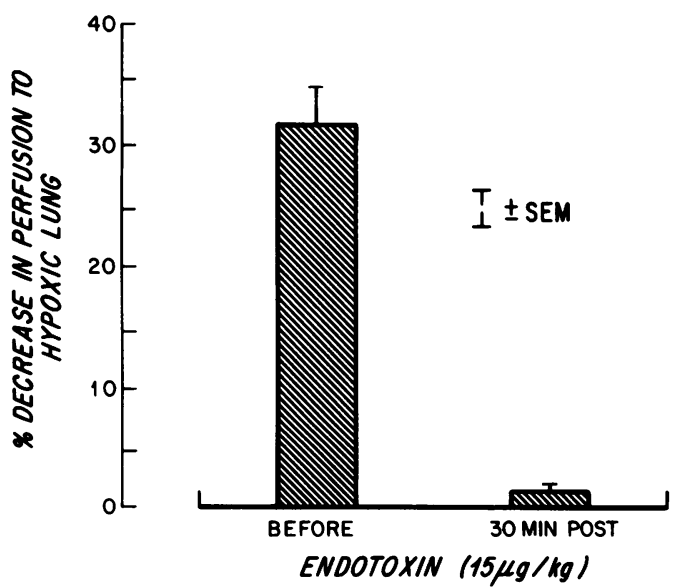

Figure 1 Influence of $15 \mu \mathrm{g} / \mathrm{kg}$ of endotoxin on alveolar hypoxic vasoconstriction. $30 \mathrm{~min}$ after intravenous endotoxin pulmonary vasoconstriction to the nitrogen-ventilated or hypoxic lung of the dog was lost. At this time thromboxane and prostacyclin levels were similarly increased at 380 and $360 \mathrm{pg} / \mathrm{ml}$. Indomethacin pretreatment preserved alveolar hypoxic vasconstriction and prevented the rise in thromboxane and prostacyclin.
In association with this hyporesponsivity there was a rise in prostacyclin from nondetectable levels in seven of eight dogs before endotoxin and at 5 min after endotoxin to a mean of $360 \mathrm{pg} / \mathrm{ml}( \pm 130 \mathrm{SEM})(P<0.01)$ with prostacyclin now detectable in all eight dogs (Fig. 2). Thromboxane levels rose from nondetectable levels in six of eight dogs before endotoxin to a mean value of $380 \mathrm{pg} / \mathrm{ml}( \pm 40 \mathrm{SEM})(P<0.01)$ in seven dogs but was still not detectable in one dog. No differences in prostanoid metabolites were consistently seen across the lung in these animals so the results given are the mean of their aortic and pulmonary artery samples. In three dogs pretreatment with indomethacin that yielded mean serum value of $4 \mu \mathrm{g} / \mathrm{ml}$ (range 2.6-6), prevented any rise in thromboxane or prostacyclin and preserved alveolar hypoxic vasoconstriction with a mean decrease of $34 \%$ to the test lung before endotoxin and a decrease of $32 \%$ after endotoxin. Thus, metabolites of thromboxane and prostacyclin clearly rose after $15 \mu \mathrm{g} / \mathrm{kg}$ of endotoxin. However, the predominant effect was one of vasorelaxation of pulmonary vessels, which was blocked by indomethacin, as was the production of thromboxane and prostacyclin.

Endotoxin, $150 \mu \mathrm{g} / \mathrm{kg}$. At this level of endotoxin a transient rise in pulmonary artery pressure was present 1-5 min after injection with return to base line by 20-30 min (Table I). By $30 \mathrm{~min}$, the lung vessels were again hyporeactive and unable to respond to alveolar hypoxia with a perfusion shift from the hypoxic lung, just as with lower dose endotoxin. In these 


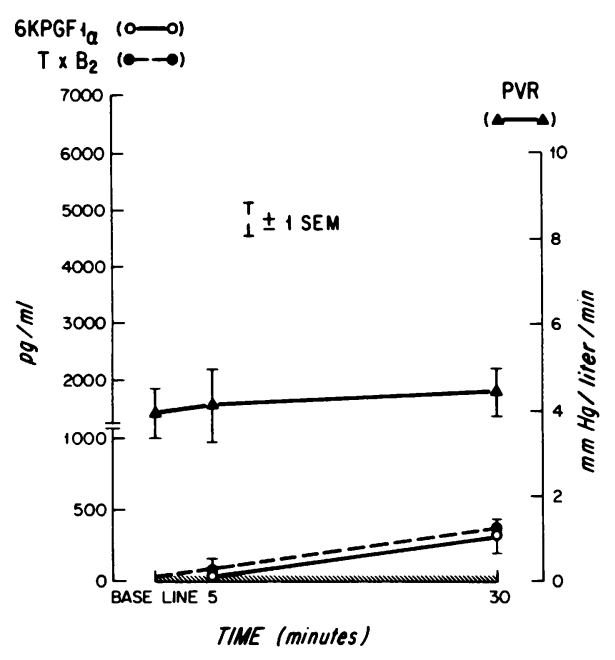

FIGURE 2 Influence of $15 \mu \mathrm{g} / \mathrm{kg}$ of endotoxin on PVR and circulating levels of thromboxane and prostacyclin. PVR was unchanged by $15 \mu \mathrm{g} / \mathrm{kg}$ of endotoxin, but the pulmonary vessels became nonresponsive to hypoxia (Fig. 1), A II, and $\mathrm{PGF}_{2 \alpha}$ at 30 min postendotoxin when circulating levels of thromboxane and prostacyclin were both significantly elevated. $\mathbb{Q}$, nondetectable; $n=8$.

dogs, as opposed to those receiving lower dose endotoxin, the systemic blood pressure fell and was significantly lower $30 \mathrm{~min}$ after $150 \mu \mathrm{g} / \mathrm{kg}$ of endotoxin (Table I). The control rise in systemic mean blood pressure during A II infusion was $58 \mathrm{~mm} \mathrm{Hg}(n=4)$ before endotoxin but was only $3 \mathrm{~mm} \mathrm{Hg}$ postendotoxin.

Levels of thromboxane rose dramatically in association with the rise in pulmonary vascular resistance (PVR) from $<50 \mathrm{pg} / \mathrm{ml}$ in all controls to a peak of 4,460 $\mathrm{pg} / \mathrm{ml}( \pm 1,350 \mathrm{SEM})$ (Fig. 3). In the group of eight dogs with samples drawn between 1 and 5 min after 150 $\mu \mathrm{g} / \mathrm{kg}$ of endotoxin, there was no significant difference in thromboxane between pulmonary artery and aortic blood. However, in all three of the dogs in which samples were obtained at $1 \mathrm{~min}$ after endotoxin, thromboxane levels were greater in aorta than in pulmonary artery with a mean difference of $1,500 \mathrm{pg} / \mathrm{ml}$. Correlation of the linear regression of maximum rise in pulmonary vascular resistance with the simultaneous rise in thromboxane was $0.89(P<0.001)$. However, PVR returned to base line by $30 \mathrm{~min}$ after endotoxin whereas thromboxane levels were lower $(P<0.01)$ but still elevated to $2,200 \mathrm{pg} / \mathrm{ml}( \pm 1,100 \mathrm{SEM})$. Prostacyclin levels after $150 \mu \mathrm{g} / \mathrm{kg}$ of endotoxin rose from $<40$ $\mathrm{pg} / \mathrm{ml}$ in all dogs to a peak of $550 \mathrm{pg} / \mathrm{ml}( \pm 400 \mathrm{SEM})$ and remained elevated at $360 \mathrm{pg} / \mathrm{ml}( \pm 135$ SEM) $30 \mathrm{~min}$ after endotoxin, which is similar to the level seen 30 min after endotoxin at a dose of $15 \mu \mathrm{g} / \mathrm{kg}$. There was no consistent difference across the lung for prostacyclin at any time.
$\mathrm{PGF}_{2 \alpha}$ was also assayed in the mixed venous and aortic blood of five of these dogs. Unlike thromboxane and prostacyclin, $\mathrm{PGF}_{2 \alpha}$ did not rise consistently after endotoxin at $150 \mu \mathrm{g} / \mathrm{kg}$. In all control animals, $P G_{2 \alpha}$ was $<100 \mathrm{pg} / \mathrm{ml}$ in mixed venous and aortic blood. In three of the animals, $\mathrm{PGF}_{2 \alpha}$ was still below $100 \mathrm{pg} / \mathrm{ml}$ after endotoxin although, in two animals, $P G_{2 \alpha}$ in aortic blood rose to 300 and $330 \mathrm{pg} / \mathrm{ml}$, respectively.

Indomethacin, at a mean serum level of $5.5 \mu \mathrm{g} / \mathrm{ml}$ (3.3-8.0) again prevented any rise in the metabolites of prostacyclin or thromboxane in response to endotoxin and prevented the transient rise in PVR with the subsequent hyporeactivity. Thus, changes in arachidonic acid metabolism seem to be related to changes in pulmonary vascular tone after endotoxin in $150 \mu \mathrm{g} / \mathrm{kg}$, and thromboxane appears to be a pulmonary vasoconstrictor. Inhibition of cyclooxygenase also prevented the fall in systemic blood pressure after endotoxin and maintained a rise of $47 \mathrm{~mm} \mathrm{Hg}$ in mean systemic blood pressure in response to A II infusion.

The interaction of prostacyclin and thromboxane after $150 \mu \mathrm{g} / \mathrm{kg}$ of endotoxin was further investigated with the thromboxane synthetase inhibitor imidazole. In five dogs treated with imidazole there was a $20-\mathrm{mm}$ $\mathrm{Hg}$ rise in systemic blood pressure, a $2-\mathrm{mm} \mathrm{Hg}$ rise in

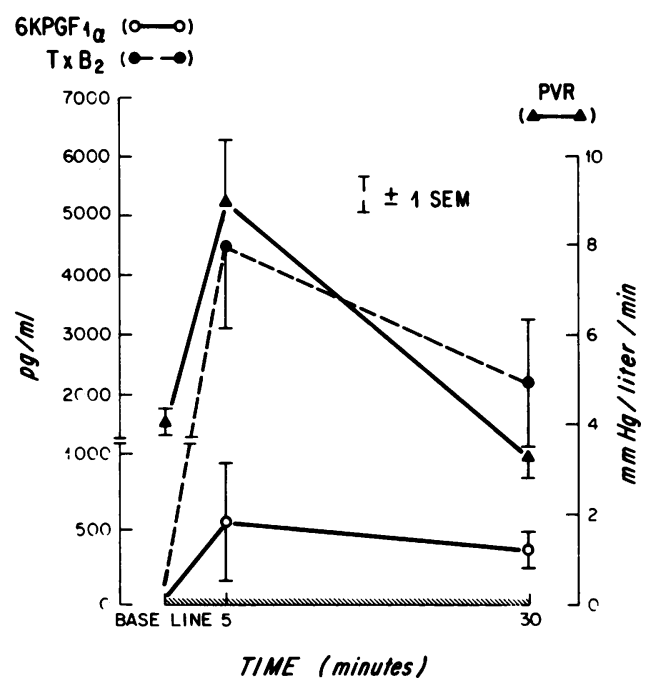

FIGURE 3 Influence of $150 \mu \mathrm{g} / \mathrm{kg}$ of endotoxin on pulmonary vascular resistance and circulating levels of thromboxanes and prostacyclin. $5 \mathrm{~min}$ after intravenous injection of endotoxin PVR more than doubled in association $(r=0.89)$ with a marked rise in level of thromboxanes and a lesser but significant $(P<0.01)$ increase in prostacyclin. $30 \mathrm{~min}$ after endotoxin when PVR was base-line and the vessels were nonreactive to alveolar hypoxia, $A$ II, and $\mathrm{PGF}_{2 \alpha}$, prostacyclin levels remained elevated $(P<0.01)$ as did thromboxane levels $(P<0.01)$ although the latter had fallen considerably. Indomethacin prevented the rise of PVR after endotoxin, the subsequent pulmonary vascular hyporesponsivity, and the

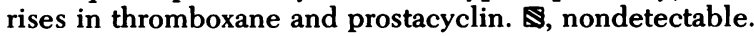


TABLE II

Influence of Imidazole on Hemodynamics

\begin{tabular}{lcccc}
\hline & $\begin{array}{c}\text { Control } \\
(n=5)\end{array}$ & $\begin{array}{c}\text { Imidazole } \\
(n=5)\end{array}$ & $\begin{array}{c}30 \text { min } \\
\text { Imidazole plus } \\
\text { endotoxin acute } \\
(n=4)\end{array}$ & $\begin{array}{c}\text { Postimidazole } \\
\text { plus endotoxin } \\
(n=4)\end{array}$ \\
\hline PAP & $14 \pm 2$ & $16 \pm 2$ & 12 & 13 \\
PCW & $5 \pm 2$ & $6 \pm 2$ & 5 & 5 \\
CO & $2.0 \pm 0.3$ & $1.9 \pm 0.3$ & 1.0 & 1.5 \\
FAP & $125 \pm 4$ & $140 \pm 4^{*}$ & 85 & 95 \\
\hline
\end{tabular}

See abbreviations in legend for Table I.

$* P<0.01$ from control.

pulmonary artery pressure (Table II), but there was no influence on hypoxic vasoconstriction as the hypoxic lung decreased its perfusion by $31 \%( \pm 2$ SEM) before imidazole and by $32 \%( \pm 3$ SEM) after imidazole. Four more dogs, immediately after completion of the imidazole infusion, were given a bolus of $150 \mu \mathrm{g} / \mathrm{kg}$ of endotoxin. Thromboxane and prostacyclin synthesis was assessed in two of these dogs and revealed no change in prostacyclin synthesis but substantial inhibition of thromboxane synthesis. Thromboxane rose from nondetectable levels to $800 \mathrm{pg} / \mathrm{ml}$ acutely and remained at $486 \mathrm{pg} / \mathrm{ml}$ at $30 \mathrm{~min}$. Prostacyclin rose to $307 \mathrm{pg} / \mathrm{ml}$ acutely after endotoxin and was $500 \mathrm{pg} / \mathrm{ml}$ at 30 min. Systemic blood pressure, pulmonary artery pressure, and cardiac output fell and remained low for $30 \mathrm{~min}$ with a trend to recovery (Table II). Pulmonary vascular resistance did rise by $50 \%$ after the endotoxin, but this rise is not interpretable because of the independent effect of cardiac output reduction on PVR (29).

Platelet function after endotoxin. Endotoxin has been noted to cause platelet clumping with trapping in the lung vasculature (13). Because platelets are also aggregated by thromboxane, we felt that part of thromboxane's hypertensive effect on lung vessels could be a result of mechanical obstruction of lung vessels by platelet plugs. In three dogs given $15 \mu \mathrm{g} / \mathrm{kg}$ of endotoxin there was no pulmonary artery pressure rise. Nevertheless, a fall in circulating platelets from $426 \times 10^{3}$ to $270 \times 10^{3}$ per ml occurred. In five dogs mixed venous and aortic platelet counts were done before $150 \mu \mathrm{g} / \mathrm{kg}$ endotoxin and were $509 \times 10^{3}( \pm 119$ $\left.\times 10^{3} \mathrm{SEM}\right)$ and $568 \times 10^{3} / \mathrm{ml}\left( \pm 119 \times 10^{3} \mathrm{SEM}\right)$, respectively. $5 \mathrm{~min}$ after endotoxin, mixed venous platelets were $70 \times 10^{3} / \mathrm{ml}\left( \pm 6.5 \times 10^{3} \mathrm{SEM}\right)$, and aortic platelets were $60.5 \times 11^{3} / \mathrm{ml}\left( \pm 4 \times 10^{3} \mathrm{SEM}\right)$, significantly less now than mixed venous levels. In three dogs treated with indomethacin $(12 \mathrm{mg} / \mathrm{kg})$ where there was no rise in thromboxane and no change in PVR, there was still a fall in platelets in mixed venous blood from $484 \times 10^{3}$ to $74 \times 10^{3}$ per ml and in aortic blood from $492 \times 10^{3}$ to $71.3 \times 10^{3}$ per $\mathrm{ml}$. Thus, plate- let plugs are unlikely responsible for the rise in pulmonary vascular resistance on a mechanical basis.

\section{DISCUSSION}

Endotoxin, in doses too small to cause pulmonary edema or shock, nevertheless induced changes in pulmonary vascular tone apparently via alterations in the arachidonic acid cascade because indomethacin blocked both the changes in prostanoid metabolism and the associated pulmonary vascular tone changes. Very low-dose endotoxin, $15 \mu \mathrm{g} / \mathrm{kg}$, produced equally elevated circulating levels of the vasoconstrictor thromboxane and the vasodilator prostacyclin with a concomitant hyporesponsivity of the pulmonary vessels, suggesting prostacyclin had the dominant influence (Fig. 2).

Endotoxin, in a still modest dose of $150 \mu \mathrm{g} / \mathrm{kg}$, induced a transient rise in PVR followed again by hyporesponsivity of the pulmonary vessels to hypoxia, A II or $\mathrm{PGF}_{2 \alpha}$. The rise in PVR correlated with a large transient release of thromboxanes, which seemed to overwhelm the rise in the vasodilator prostacyclin and resulted in pulmonary vasconstriction (Fig. 3). The interaction between the apparent vasconstrictor thromboxane and the vasodilator prostacyclin is complex, however, because the pulmonary vessels became unresponsive while the circulating levels of thromboxanes were still quite elevated compared with base line $(P<0.01)$ and compared with the sustained but lower circulating levels of prostacyclin.

Several possibilities exist to explain this phenomenon. (a) Prostacyclin may be more potent than the thromboxane on pulmonary vessels. This cannot be tested directly because of the nonavailability of sufficient thromboxane $A_{2}$ to infuse. $(b)$ The ratio of thromboxane $A_{2}$ to $T \times B_{2}$ may be much higher early after endotoxin and thromboxane $A_{2}$, although rapidly converted to $\mathrm{TxB}_{2}$, may be the more potent pulmonary vasoconstrictor as it is the more potent systemic vasoconstrictor (16). (c) $\mathrm{TxB}_{2}$, the stable metabolite of thromboxane $A_{2}$ and itself a moderately active vasoconstrictor, has been shown to produce tachyphylaxis during repeated infusions in dogs (30). Thus the pulmonary vessels in this study may be losing responsivity to the still high circulating levels of $\mathrm{TxB}_{2}$. $(d)$ Finally, it is possible that other vasoconstrictor prostanoids were released by endotoxin and assisted in the vasoconstriction associated with the rise in thromboxane. Endotoxin in a shock dose of $1 \mathrm{mg} / \mathrm{kg}$ releases the pulmonary vasoconstrictors $\mathrm{PGF}_{2 \alpha}$ and $\mathrm{PGE}_{2}(8,9)$. We assayed for $\mathrm{PGF}_{2 \alpha}$ release after $150 \mu \mathrm{g} / \mathrm{kg}$ of endotoxin and did not detect a consistent rise. The lung is capable of rapidly metabolizing $\mathrm{PGF}_{2 \alpha}$ and perhaps more was released than we assayed and contributed to the transient vasoconstriction. The intermediates of the arachidonic 
acid cascade, the cyclic endoperoxides, are thought to be potent pulmonary vasoconstrictors. This conclusion is derived from studies done with a stable analogue of the cyclic endoperoxides, which has a longer half-life than the native compound (31). Thus natural cyclic endoperoxides may not be as potent in inducing vasoconstriction because of their rapid turnover. Nevertheless, endogenously released cyclic endoperoxides cannot be measured at the present time because of their short half-life. They are the precursors of the thromboxanes and prostacyclin and likely rise to some degree after endotoxin.

We attempted to separate the role of thromboxane from all the other prostanoids including the cyclic endoperoxides by inhibiting thromboxane synthetase with imidazole, thus preventing conversion of the cyclic endoperoxides to thromboxane. Imidazole alone did not affect cardiac output but unfortunately, imidazole plus $150 \mu \mathrm{g} / \mathrm{kg}$ of endotoxin produced a drastic fall in cardiac output (Table II). Thromboxane levels rose only mildly compared with nonimidazole treated animals given $150 \mu \mathrm{g} / \mathrm{kg}$ of endotoxin while the rise in prostacyclin was unaffected. Pulmonary artery pressure fell but not as markedly as did cardiac output. Thus, PVR rose. This cannot be used, however, to suggest the pulmonary vessels were actively constricting in the absence of a marked rise in the thromboxanes because the passive phenomenon of PVR is to rise in response to a fall in cardiac output (29). Also, imidazole alone produced some systemic and pulmonary vasoconstriction apparently by an action independent of its effect to inhibit production of the vasoconstrictor thromboxanes. Thus, we are unable to determine the relative potencies of the endogenously released thromboxanes and prostacyclin as the influence of other vasoconstrictor prostanoids could not be eliminated. Thromboxanes, however, would seem to be pulmonary vasoconstrictors. Our results are similar to those found in the sheep after infusion of activated complement (31). In the sheep activated complement produced a greater rise in PVR than did endotoxin in our dogs but this may be a dose-related difference. The sheep, likewise, had a much larger rise in thromboxane although prostacyclin increased only to a level similar to that seen in our endotoxin dogs. Thus endotoxin and activated complement had similar results on prostanoid metabolism supporting earlier contentions that endotoxin activates complement as part of its pathogenic profile.

Recent studies have shown that the lung produces thromboxane and prostacyclin $(32,33)$. We were unable to identify the origin of the prostanoids after endotoxin as there were no statistical differences between pulmonary artery and pulmonary venous levels. There was a trend, however, after $150 \mu \mathrm{g} / \mathrm{kg}$ of endotoxin for aortic levels of thromboxane to exceed those in pulmonary artery in samples drawn at $1 \mathrm{~min}$ after endotoxin. Perhaps earlier sampling at $1 \mathrm{~min}$ or less after endotoxin would reveal the lung as the source of thromboxane. However, it may be that in vivo endotoxin induced a general systemic and lung output of the prostanoids that prevented us from recognizing the lung's contribution.

Platelets are affected by endotoxin, and their levels fall dramatically. Indomethacin failed to prevent this fall in platelet levels although it did prevent the transient pulmonary hypertension, as has been previously noted (12). Thus, platelet plugs do not mechanically produce the pulmonary hypertension. Platelets, however, can be a source of thromboxane, and our data do not exclude platelet distortion as a mechanism of thromboxane production. Others, however, have produced endotoxin pulmonary vasoconstriction in severely platelet-deficient animals and make platelets less likely to be the only source of thromboxane (13).

The increased production of two different end products of the arachidonic acid cascade, thromboxane and prostacyclin, after low-dose endotoxin, supports the thesis that endotoxin is increasing phosopholipid breakdown, which increases availability of arachidonic acid to move through the cascade. The dose-response differences in endotoxin on thromboxane and prostacyclin production could reflect a role for endotoxin in modifying pathways within the arachidonic acid cascade. More likely, however, is the alternative explanation that prostacyclin synthetase is very active but easily saturated (34). Thus, at low doses of endotoxin with only small amounts of arachidonic acid being converted to the intermediary cyclic endoperoxides, prostacyclin synthetase is at least equal to thromboxane synthetase but at higher doses of endotoxin with more arachidonic acid entering the cascade, prostacyclin synthetase is saturated allowing more cyclic endoperoxides to be diverted to thromboxane or other prostanoids.

The systemic circulation was unaffected by $15 \mu \mathrm{g} / \mathrm{kg}$ of endotoxin. Mean femoral artery blood pressure did fall by $13 \mathrm{~mm} \mathrm{Hg} 30 \mathrm{~min}$ after $150 \mu \mathrm{g} / \mathrm{kg}$ of endotoxin although cardiac output was unchanged. Of note, however, is that even at $15 \mu \mathrm{g} / \mathrm{kg}$ of endotoxin, the constrictor response of the systemic circulation to A II was blunted, and at $150 \mu \mathrm{g} / \mathrm{kg}$ of endotoxin the constrictor response to A II of the systemic vessels was lost. Indomethacin preserved the systemic response that suggests that prostacyclin was affecting the systemic vessels in a fashion similar to the effect on pulmonary vessels. No rise in systemic blood pressure was seen in association with the rise in thromboxane. The reason for this is unclear as thromboxane is thought to be a potent systemic vasoconstrictor. Perhaps the rise in systemic blood pressure was not noted because of a direct action of endotoxin to decrease the force of myo- 
cardial contraction (35) or perhaps because of a relatively greater sensitivity of the peripheral vasculature to prostacyclin than to thromboxane. It is also possible that although we did not clearly demonstrate the lung to be the source of the thromboxane, it nevertheless is that, and because of the short half-life of thromboxane $\mathrm{A}_{2}(<30 \mathrm{~s})$, the effect on lung vessels was predominant.

In summary, our studies support those of previous workers who have suggested with the use of cycloxygenase inhibitors that alterations in prostanoid metabolism are responsible for the changes in pulmonary vascular tone after low-dose endotoxin. We have shown by assay of endogenously produced prostanoids that both thromboxane and prostacyclin are released by endotoxin and that the resulting interplay of these substances can at least substantially account for the observed changes in pulmonary vascular tone. Our studies indicate an appreciation of the in vivo physiologic role of prostanoid mediators must involve measurement of the multiple different prostanoids simultaneously.

\section{ACKNOWLEDGMENTS}

This work was supported by U. S. Public Health Service grants HL-07354 and HL-23591.

\section{REFERENCES}

1. Proctor, R. A. 1979. Endotoxin in vitro interactions with human neutrophils: depression of chemiluminescense, oxygen consumption, superoxide production and killing. Infect. Immun. 25: 912-921.

2. Fine, D. P. 1974. Activation of the classic and alternate pathways by endotoxin. J. Immunol. 112: 763-769.

3. Athens, J. W., O. P. Haab, S. O. Raab, A. M. Mauer, H. Ashenbruker, G. E. Cartwright, and M. M. Wintrobe. 1961. Leukokinetic studies IV. The total blood, circulating and marginal granulocyte pools and the granulocyte turnover rate in normal subjects. J. Clin. Invest. 40: 989-995.

4. Horowitz, H. I., R. M. Des Prez, and E. W. Hoor. 1962. Effects of endotoxin on rabbit platelets. II. Enhancement of platelet factor 3 activity in vitro and in vivo. J. Exp. Med. 116: 619-633.

5. Henshaw, L. B., C. M. Brake, and T. E. Emerson. 1965. Biochemical and pathological alterations in endotoxin shock. In Shock and Hypotension: Pathogenesis and Treatment. L. J. Mills, editor. Grune \& Stratton, Inc. New York. 431-441.

6. Clauser, F. L., J. Palmer, S. Cecconi, W. Schoolcraft, I. Wells, H. Novey, P. Egan, and D. Smeltzer. 1977. The effect of endotoxin on the mast cell c'AMP system. Ann. Allergy. 38: 104-107.

7. Davis, R. B., W. R. Meeker, and D. G. McQuarrie, 1960. Immediate effects of intravenous endotoxin on serotonin concentrations and blood platelets. Circ. Res. 8: 234-239.

8. Anderson, F. L., W. Jubiz, T. J. Tsagaris, and H. Kuida. 1975. Prostaglandin $F$ and $E$ levels during endotoxininduced pulmonary hypertension in calves. Am. J. Physiol. 228(5): 1479-1482.
9. Anderson, F. L., W. Jubiz, T. J. Tsagaris, and H. Kuida. 1975. Endotoxin-induced prostaglandin $E$ and $F$ release in dogs. Am. J. Physiol. 228(2): 410-414.

10. Faden, A. I., and J. W. Holoday. 1980. Naloxone treatment of endotoxin shock: stereospecificity of physiologic and pharmacologic effects in the rat. J. Pharmacol. Exp. Ther. 212: 441-447.

11. Reeves, J. T., and R. F. Grover. 1974. Blockade of acute hypoxic pulmonary hypertension by endotoxin. J. Appl. Physiol. 36: 328-332.

12. Weir, E. K., J. Mlczoch, J. T. Reeves, and R. F. Grover. 1976. Endotoxin and prevention of hypoxic pulmonary vasoconstriction. J. Lab. Clin. Med. 88: 975-983.

13. Weir, E. K., J. Mlczoch, J. Seavy, J. J. Cohen, and R. F. Grover. 1976. Platelet antiserum inhibits hypoxic pulmonary vasoconstriction in the dog. J. Appl. Physiol. 41: 211-215.

14. Mlczoch, J., E. K. Wier, R. F. Grover, and J. T. Reeves. 1978. Pulmonary vascular effects of endotoxin in leukopenic dogs. Am. Rev. Respir. Dis. 118(6): 1097-1099.

15. Cook, J. A., W. C. Wise, and P. V. Habushka. 1980. Elevated thromboxane levels in the rat during endotoxic shock. J. Clin. Invest. 65: 227-230.

16. Eilis, E. F., O. Oelz, L. J. Robert, N. A. Payne, B. J. Sweetman, A. S. Nies, and J. A. Oates. 1976. Coronary arterial smooth muscle contraction by a substance released from platelets: Evidence that it is thromboxane $A_{2}$. Science (Wash. D. C.). 193: 1135-1137.

17. Svenson, J., and M. Hamburg. 1976. Thromboxane $A_{2}$ and prostaglandin $\mathrm{H}_{2}$ : potent stimulators of the swine pulmonary artery. Prostaglandins. 12: 943-950.

18. Kadowitz, P. J., B. M. Chapnick, L. P. Feigen, A. L. Hyman, P. K. Nelson, and E. W. Spannhake. 1978. Pulmonary and systemic vasodilator effects of the newly discovered prostaglandin, PGI $_{2}$. J. Appl. Physiol. Respir. Environ. Exercise Physiol. 45: 408-413.

19. Bult, H., J. Beetens, and A. G. Herman. 1980. Blood levels of 6-oxo-prostaglandin $F_{1 \alpha}$ during endotoxin-induced hypotension in rabbits. Eur. J. Pharmacol. 63: 47-56.

20. Hales, C. A., and H. Kazemi. 1974. Hypoxic vascular response of the lung: effect of aminophylline and epinephrine. Am. Rev. Respir. Dis. 110: 126-132.

21. Strieder, D. J., B. A. Barnes, S. Aronow, P. S. Russell, and H. Kazemi. 1967. ${ }^{133}$ Xenon study of ventilation and perfusion in normal and transplanted dog lung. J. Appl. Physiol. 23: 359-366.

22. Kazemi, H., P. E. Bruecke, and E. F. Parsons. 1972. Role of the autonomic nervous system in the hypoxic response of the pulmonary vascular bed. Respir. Physiol. 15: 245-254.

23. Miller, M., and C. A. Hales. 1980. Stability of alveolar hypoxic vasoconstriction with intermittent hypoxia. $J$. Appl. Physiol. 49: 846-850.

24. Levine, L., R. M. Gutierrez-Cernosek, and H. Vannanakis. 1971. Specificities of prostaglandin $B_{1}, F_{1 \alpha}$, and $F_{2 \alpha}$ antigen-antibody reactions. J. Biol. Chem. 246: 6782-6785.

25. McCosh, E. J., D. L. Meyer, and J. Dupont. 1976. Radioimmunoassay of prostaglandins $E_{1}, E_{2}$, and $F_{2 \alpha}$ in unextracted plasma, serum and myocardium. Prostaglandins. 12: 471-486.

26. Delean, A. P., P. J. Munson, and D. Rodbard. 1978. Simultaneous analysis of families of sigmoidal curves: application to bioassay, radioligandassay, in physiological dose-response curves. Am. J. Physiol. 235: E97-E102.

27. Bahn, A. K. 1972. In Basic Medical Statistics. Grune \& Stratton, Inc., New York. 144-156.

28. Hales, C. A., D. J. Kanarek, B. Ahluwalia, A. Latty, J. 
Erdmann, S. Javaheri, and H. Kazemi. 1981. Regional edema formations in isolated perfused dog lungs. Circ. Res. 48: 121-127.

29. Murray, J. F., R. B. Kanf, and J. A. Nadel. 1969. Viscosity effects on pressure-flow relations and vascular resistance in dogs' lungs. J. Appl. Physiol. 27: 336-341.

30. Friedman, L. S., T. M. Fitzpatrick, M. F. Broom, P. W. Ramwell, J. C. Rose, and P. A. Kot. 1979. Cardiovascular and pulmonary effects of thromboxane $\mathrm{B}_{2}$ in the dog. Circ. Res. 44: 748-751.

31. Bowers, R. E., E. F. Ellis, K. L. Brigham, and J. A. Oates. 1979. Effects of prostaglandin endoperoxides on the lung circulation of unanesthetized sheep. J. Clin. Invest. 63: 131-137.

32. Gryglweski, R. F., R. Korbut, and A. Ocetkiewicz. 1978.
Generation of prostacyclin by lungs in-vivo and its release into the arterial circulation. Nature (Lond.). 273: 765-767.

33. Berti, F., G. Folco, A. Giachetti, S. Malandrino, C. Omni, and T. Vigano. 1980. Atropine inhibits thromboxane $A_{2}$ generation in isolated lungs of the guinea pig. $\mathrm{Br} . \mathrm{J}$. Pharmacol. 68: 467-472.

34. Sun, F. F., J. P. Chapman, and J. C. McGuire. 1978 Metabolism of prostaglandin endoperoxide in animal tissues. Prostaglandins. 14: 1055-1074.

35. Cho, Y. W. 1972. Direct cardiac action of endotoxin (36856). Proc. Soc. Exp. Biol. Med. 141: 705-707.

36. Cooper, J. D., J. W. D. McDonald, M. Ali, E. Menkes, L. Masterson, and P. Klement. 1980. Prostaglandin production associated with the pulmonary vascular response to complement activation. Surgery (St. Louis). 88: 215-221. 